\title{
PAI ESPECIALIZAÇÃO FLEXIVEL: UMA ALTERNATIVA PROMISSORA PARA O DESENVOLVIMENTO ECONÔMICO DE REGIÕES SUBDESENVOLVIDAS
}

ARTIGO

*José Luiz Celeste

Especialização flexível como uma alternativa para aumento do nível de emprego.

Flexible specialization as an alternative to improve employment level.

\section{CONCEITUAÇÃO}

Como tantas outras definições em Ciência, a de Especialização Flexível (EF) é controversa. Já de saída, a idéia de "Especialização" contradiz a idéia de "Flexível".
Stricto sensu, a EF é a manufatura de produtos variados através de equipamento versátil e de mão-deobra multiqualificada. Contudo essa definição nāo é satisfatória, já que se aplica a casos que fogem ao conceito que se deseja exprimir. Por exemplo, as ma-

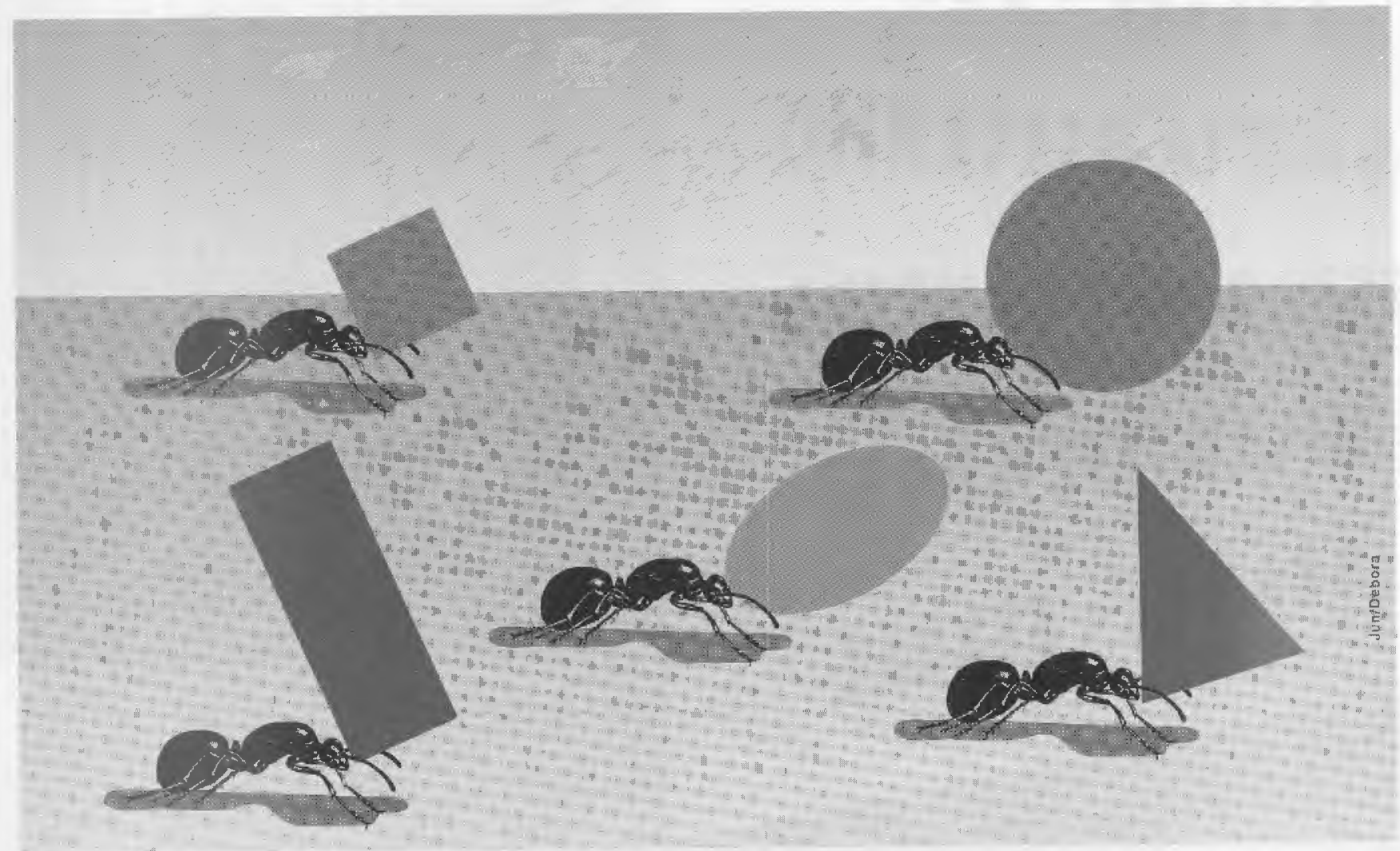

*Professor Assistente do Departamento de Informática e Métodos Quantitativos da EAESP/FGV. 
nufaturas de roupa que atuam informalmente no mercado, aviltando o salário de seus funcionários, ficariam incluídas na $E F$, o que não se pretende. A idéia de aprimorar a qualidade do produto está sempre presente na EF, o que não é o caso dessas manufaturas de roupas.

Lato sensu, a EF significa uma inovação no processo produtivo e uma estratégia de fast product, isto é, entrega imediata do produto para minimizar o nível de estoque. Esta definição, por sua vez, subentende "sucesso" em seus termos, o que também não se preconiza.

Além disso, existe outra dificuldade: o termo EF tem sido usado extensivamente na literatura, por autores que lhe atribuem significados diferentes. Abrange a situação de pequenas firmas que se articulam cooperativamente e também aquela em que uma grande firma (empresa mãe) subcontrata empresas pequenas, como ocorre no Japão. Abrange também o caso dos grupos semi-autôno$\operatorname{mos}^{1}$, estrutura adotada internamente em certas empresas.

Especialização flexível (Flexible Specialization) também não deve ser confundida com Sistemas Industriais Flexíveis (Flexible Manufacturing Systems ${ }^{2}$ ) que são grupos de centros de trabalho (cells) robotizados, capazes de produzir várias peças ou partes, com mínima intervenção de trabalho humano. A especialização flexível ainda se distingue de Tecnologia de Grupo (Group Technology ${ }^{3}$ ), termo freqüentemente usado para identificar famílias de partes que podem ser produzidas por operações similares. $\mathrm{O}$ significado de tecnologia de grupo também pode ser estendido à organização, planejamento e controle das funções dos trabalhadores que operam esses centros de trabalho.

Anna Pollert ${ }^{4}$ desenvolve criticamente os aspectos ideológicos do termo "flexível". Argumenta que o conceito não é novo; tem sido usado desde a década de 60 , e se tornou uma panacéia forjada sobre uma linguagem duvidosa, na tentativa de promover integração social numa época de insegurança e desemprego. Segundo essa autora, a idéia de "flexibilidade" move-se num espaço em que a esquerda e a direita estão em consenso, já que explora questões de organização do trabalho, desviando-se daquelas ligadas à estrutura do capital, de investimento, taxas de câmbio e relações sindicais. As palavras radicais de Anna Pollert, no entendimento do autor deste artigo, são uma advertência no sentido de que nenhum assunto ou modelo deve ser transformado em panacéia; a EF apresenta características no mínimo dignas de reflexão por parte dos estudiosos de Administração.

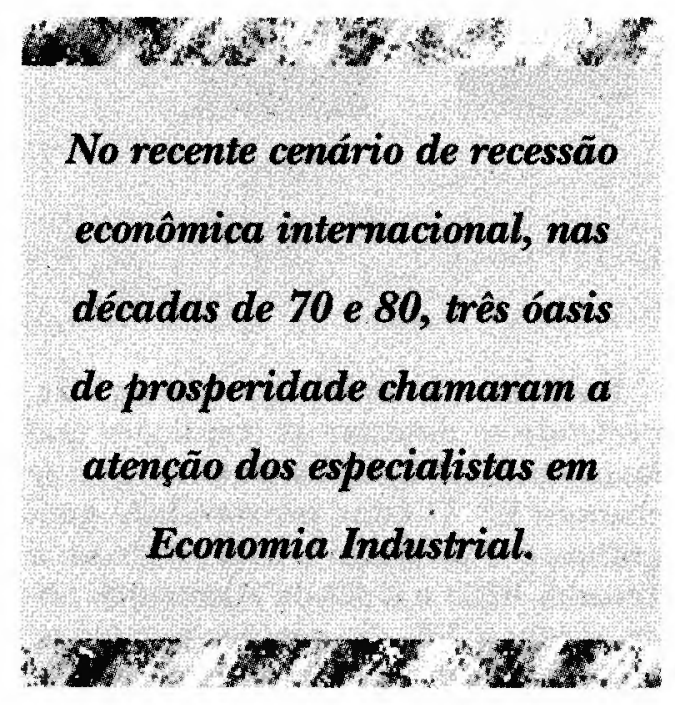

\section{O CONTEXTO}

Para superar o impasse da definicão, será examinado o contexto em que esse modelo de EF surgiu e se impôs aos olhos do mundo. No recente cenário de recessão econômica internacional, nas décadas de 70 e 80 , três óasis de prosperidade chamaram a atenção dos especialistas em Economia Industrial. Eram eles: o Nordeste da Itália (região de Bolonha, Florença, Ancona e Veneza, chamada de terceira Itália), o sul da Alemanha (região de Baden-Würtenberg) e o Japão.

Serão examinados os casos da Alemanha e da Itália, sendo que o do Japão foi deixado de lado, por caracterizar uma situação diferente, que não pode ser chamada de EF. Nesse país, as grandes empresas sub-contratam e desenvolvem outras empresas, terminando por formar uma rede de produção muito ordenada e eficiente, que permite reduzir os níveis de estoque, os custos de retrabalho e ou-
1. PIERCE, J. A., RAVLIN. E.C. The design and activation of self regulating work groups. Human Relations, v. 40, n. 11, p. 75182, 1987; ver também: BUCHANA, David A. The development of Job Design theories and techniques. West Mead: Saxon House, 1987.

2. MC DERMOT, KEVIN, KAMISETTY, K. V. Developing a FMS using IE tools and principles. Industrial Engineering, Dec. 1991.

3. KNIGH, Donald 0., WALL M. L. Using group technology for improving communication and coordination among teams of workers in manufacturing cells. Industrial Engineering, Jan. 1989; ver também HAM, Inyong. Group technology aplications for Higher manufacturing productivity. S.N.T., mimeo.

4. POLLERT, Anna. Dismantling flexibility. Capital and Class, v. 34, Spring, 1988. 
tros. O modelo japonês poderia ser esquematizado conforme se mostra na figura 1.

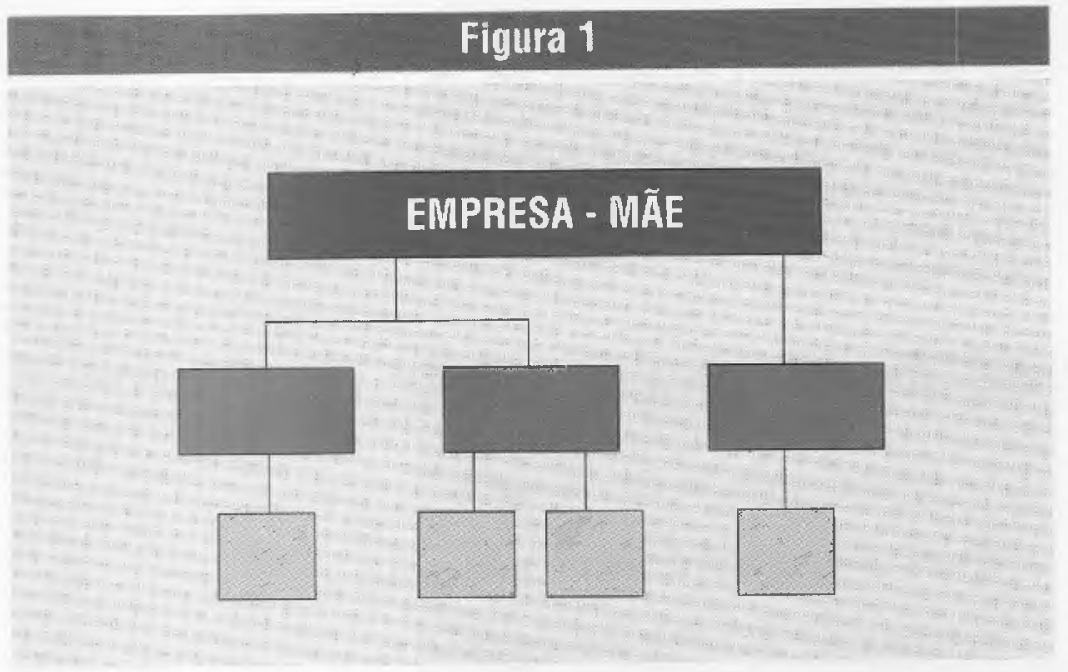

5. SABEL, Herrigel et al. Regional prosperities compared: Massachussets and BadenWürttemberg in the 1980s. Economy and Society, v. 18, n. 4, Nov. 1989

6. SCHMITZ, Hubert. Growth contraints on small-scale manufacturing in developing countries: a critical review. Word Development, v. 10, n. 6, p. 42950, 1982

7.THOMPSON, Grahame. Flexible specialization, industrial districts, regional economies: strâtegies for socialists? Economy and Society, v. $18, n .4$, Nov. 1989.
Examinando essas regiões européias, pretende-se detectar as condições que favoreceram o aparecimento do que se chamou EF. O fator proximidade geográfica é o primeiro a sobressair-se: a Terceira Itália e o sul da Alemanha, onde surgiu a EF, são regiões pequenas, onde as distâncias não representam maior problema.

Em seguida, observa-se uma forte tradição de cultura artesanal que, historicamente, nunca foi eliminada por completo da Europa pelos anos de ouro da produçãọ em massa.

Em terceiro lugar, o mercado consumidor europeu, diferentemente do americano, apresenta aspirações instáveis, é insatisfeito com produtos padronizados.

Sabel, Herrigel et al. discutem em seu artigo $^{5}$ as razões do declínio da manufatura têxtil em Massachussets em conmo em Baden-Württemberg, na década de 80. Algumas razões da uniformidade e da massificação do mercado americano são aí colocadas em perspectiva.

Os autores explicam que esse declínio não ocorreu por falta de capital ou incapacidade de inovação, mas por uma estrutura verticalizada em que os produtores de maquinaria de fiação e tecelagem dominavam financeiramente as tecelagens, ofertando uma gama estreita desses equipamentos. Como as tecelagens eram financiadas pelos produtores de traste com a prosperidade do mesmo ra- bens de capital, os pagamentos se faziam, muitas vezes, através de estoques de produtos têxteis. Desse arranjo resultou uma situação sui generis, em que as tecelagens, subservientes, ficavam atadas aos fabricantes de maquinaria, com pouco poder de decisão sobre o equipamento que compravam. Os produtores de maquinaria, por sua vez, mais distantes do mercado consumidor, dispunham de estoques de produtos têxteis que eram "impingidos" aos consumidores finais. Estes últimos, em grande parte imigrantes recentes, formavam um mercado maleável, conformando-se com a estreita lista de produtos oferecidos.

$\mathrm{O}$ quarto aspecto consiste na articulação que se estabeleceu entre as pequenas unidades produtivas. Enquanto isoladas, os entraves impostos por suas próprias limitações constituíam barreiras dificilmente superáveis. As estatísticas mostram que a taxa de sobrevivência é baixa entre pequenas e micro-empresas. Em se tratando do setor informal da economia, é difícil apresentar dados nesse sentido, muito embora seja razóavel afirmar que as razões para que o mesmo ocorra sejam semelhantes: dificuldades de acesso às fontes de matérias-primas, aos financiamentos, às informações em geral, além de fatores culturais. A tudo isso, no plano teórico, acrescenta-se um viés devido ao background teórico do analista, cujo entendimento do fenômeno se faz através dos modelos tradicionais estabelecidos pela Teoria de Administração e criados pela observação da grande empresa. ${ }^{6} \mathrm{~A}$ cooperação entre as unidades produtivas veio a desencadear um processo de fabricação novo: o produto passou a percorrer uma rota através de equipamentos e instalações de diferentes unidades produtivas autônomas. Nessa rede de produção, cada unidade produtiva não sabe precisamente 0 que deverá fabricar mas sabe que precisa contar com a colaboração dos operários e das unidades subcontratadas para ir ao encontro da demanda eventual dos mercados. ${ }^{\text {? }}$

Para melhor compreensão das rotas de produção e de por quê a cooperação é um elemento chave na $E F$, veja-se o exemplo: um fabricante de marionetes envia partes do seu produto para serem 
pintadas em alguma unidade produtiva, e contrata a confeçcão das roupas do brinquedo numa segunda unidade. Ele próprio faz a montagem e os acabamentos. Se, a partir dum certo momento, ele quiser mudar o caráter da marionete, vai buscar em outras unidades produtivas o auxílio necessário. A rede produtiva, como um todo, torna-se flexível e a mudança não implica gastos de alteração da linha de produção. Fica fácil perceber por que a atitude de colaboração é essencial para o funcionamento deste modelo.

Observa-se, ainda no contexto europeu, a existência de um mercado de oferta de equipamentos novos e usados, a disponibilidade de serviços de manutenção e a colaboração entre as unidades produtivas para transmitir know-how.

Finalmente, avulta a oferta de mãode-obra especializada e o alto rível tecnológico das sociedades em questão.

\section{A ESTRUTURA}

O modelo de EF observado no paradigma europeu é mostrado na figura 2.

Dentro do círculo da figura 2, representa-se a rede das unidades produtivas que interagem. Cada uma destas unidades possui uma "especialização", isto é, presta apena um tipo de serviço. Sua produção é focalizada. A "flexibilidade" diz respeito ao conjunto de todas as unidades. É um atributo do conjunto. Essa comunidade de manufaturas atende ao mercado (dinâmico e volátil), adaptando-se a ele como um todo, por ser esse todo, flexível. Isso ocorre graças a uma dinâmica de complementação e cooperação que constituem as relaçōes de produçāo entre as unidades produtivas.

\section{A EFICIÊNCIA DO MODELO DE EF}

A questão da medida da eficiência, tal como é tratada atualmente, contrasta eficiência grupal com eficiência individual. A premissa básica da Teoria dos Sistemas Sócio-Técnicos, da qual a medida da eficiência grupal se derivou, é que, nas organizações produtivas, os aspectos técnicos e os sociais são inseparáveis. A otimização global subentende que os componentes dos sistemas técnicos e sociais antecedem o projeto organizacional. $O$ entendimento destes aspectos facilita a integração dos sistemas e a identificaçāo de uma metodologia que naturalmente segmenta o processo total em grupos de atividades inter-relacionadas, pelas quais os grupos (não os indivíduos) são coletivamente responsáveis. ${ }^{8}$ William N. Cooke ${ }^{9}$ relata os resultados inferidos a partir de uma amostra de 430 indústrias das quais 194 apresentaram respostas utilizáveis. Não pôde ser rejeitada a hipótese de que, quanto menor for o engajamento em programas baseados em grupos, tanto menor será o índice de produtividade e também o nível de qualidade dos produtos.

No caso da EF, o conceito de eficiência e desempenho é apenas análogo ao de grupos de trabalho. O grupo de trabalho, sobre o qual está elaborada a discussão acima, é sempre interno às gran-

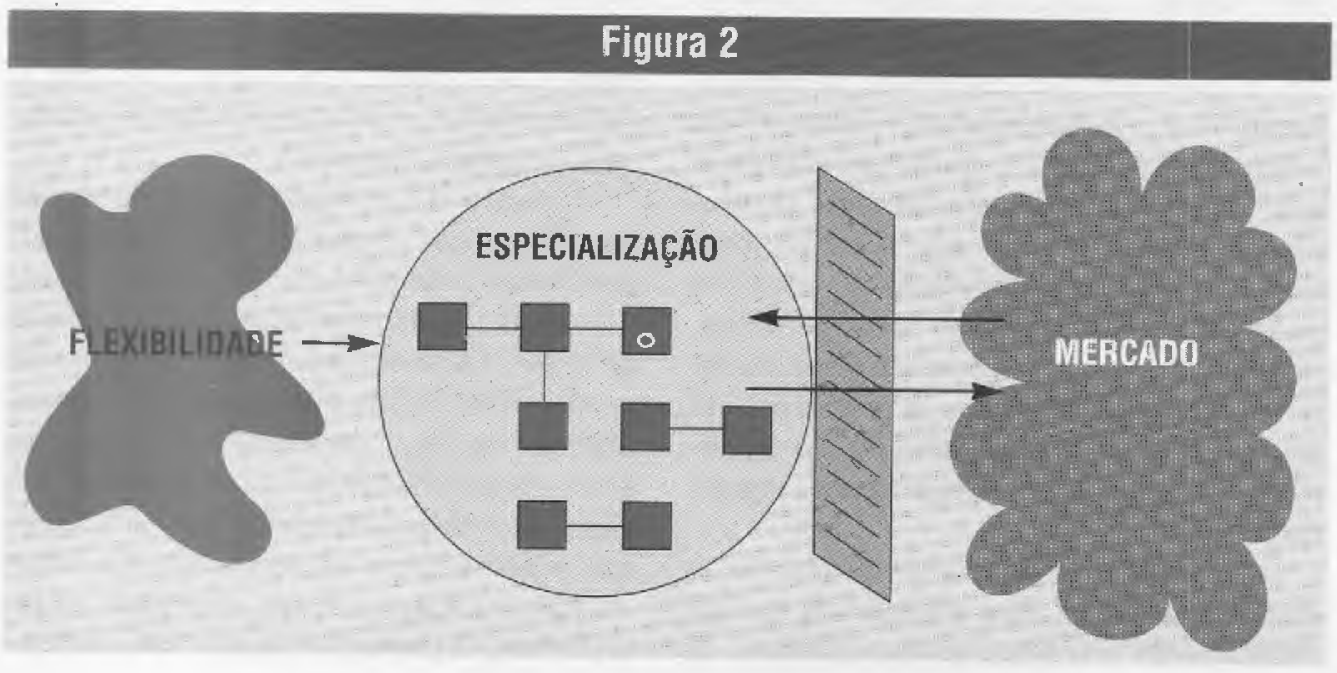

8. PEARCE II, John A., RAVLIN C. Elizabeth. The design and activations of self-regulating, work groups. Human Relations, v. 40, ก. $11,1987$.

9. COOKE, W. N. Improving productivity and quality through collaboration. Industrial Relations, v. 28, ก. 2. 
des empresas. O que se avalia, na EF, é o desempenho de todo o conjunto de pequenas unidades produtivas, abrangendo uma região geográfica. Evidenciouse, nessas regiões, o crescimento real de empregos, ao lado de uma prosperidade econômica que constrastava com a redução do nível de atividade e de emprego das grandes indústrias.

O sucesso desse desempenho demonstrou que não é o tamanho da empresa o que está associado à prosperidade mas, sim, as relações entre as unidades produtivas.

O papel da competição é um aspecto que pode ser debatido neste momento. Se a EF baseia sua robustez numa atitude de colaboracão, sem a qual a rede de unidades produtivas não é eficaz, deixa de existir competição dentro dessa estrutura?

\section{COMPETIÇÃO VERSUS COLABORAÇÃO}

Se duas unidades produtivas prestam o mesmo serviço, em princípio, elas poderiam competir entre si. Contudo, dentro da rede produtiva, essas duas unidades podem pertencer a diferentes rotas, ou seja, a diferentes caminhos seguidos por produtos diferentes, ou ainda pelo mesmo produto.

A empresa tradicional concorre no mercado de forma diferente. Há um ou mais produtos bem caracterizados por suas marcas, imagens, pontos de venda etc. Tudo isso forma um bloco onde a imagem do produto se funde à imagem da empresa. Portanto, o produto é essencial, mesmo quando se chama o serviço de produto. Nas unidades produtivas da $\mathrm{EF}$, o produto não interessa. $\mathrm{O}$ serviço prestado é o que interessa, e esse serviço pode ser aplicado a qualquer produto que venha a passar pela unidade produtiva em questão. Esse fato dissolve bastante a idéia de competição. $O$ produto passa a ser secundário, a competição, quando há, se faz em termos de qualidade do serviço prestado. A estrutura da EF propicia o aprimoramento da qualidade, ficando a competição num segundo plano.

Do ponto de vista administrativo, o deslocamento do eixo de medida de eficiência tem implicações categóricas. $\mathrm{O}$ conceito de estratégia, por exemplo, até então formulado a partir do interior da empresa, passa a ser inadequado para o modelo de especialização flexível. A estratégia e o planejamento referem-se ao conjunto global dessas empresas.

Além do aspecto estratégico, sugerese que as relações de trabalho, a postura do empregado, seu comportamento e motivação podem ser encarados sob nova perspectiva. A estrutura do poder muda. O sistema de captação de recursos financeiros e o custeio da produção têm outro aspecto. A organização do trabalho se transforma e a comercialização deixa de impor hábitos ao mercado, passando a ouvi-lo e a interpretá-lo mais intensamente.

Em suma, pressente-se que os conceitos e técnicas de Administração, elaborados sempre a partir do interior da empresa, podem vir a ser revistos, considerando o tecido das relações entre empresas como nova base para formulação de modelos administrativos. A perspectiva da Teoria da Administração passa a ser de fora para dentro.

\section{A EF NOS PAÍSES EM DESENVOLVIMENTO}

O processo de industrialização dos países do Terceiro Mundo ocorreu como um rolo compressor que desarticulou, em seu percurso, todos os núcleos autóctones de organização do trabalho, formados lentamente no decorrer da história destes países. Algumas dessas estruturas sucumbiram definitivamente. Outras subsistem até hoje, em regiões específicas; por exemplo, no Brasil, as confecções de redes e malhas no Nordeste e a indústria de sapatos no Sul e, em Kumasi/Ghana, a atividade industrial em pequena escala.

O ponto de contato entre esses núcleos de organização do trabalho e a experiência européia de EF é, mais uma vez, a eficiência econômica num período de crise. Deve-se observar, contudo, ser a crise dos países em desenvolvimento diversa de sua contrapartida européia: além do difícil esforço para romper o estágio de subdesenvolvimento, o problema relativamente novo da dívida externa passou a agravar-se, sorvendo as receitas de exportação. Com isso, limita- 
ram-se as importações, e as matérias-primas e partes de reposição foram desaparecendo do mercado.

Nessa situação, de acordo com Schmitz, quem possuísse maior capacidade de adaptação sobreviveria. Ora, a empresa grande, dado o vulto de sua capacidade instalada, é, nesse sentido, menos versátil que a pequena. ${ }^{10}$

Schmitz continua: "Observou-se em Ghana que, após um periodo de acentuado declínio, com crescimento negatioo do PNB entre 1980 e 1983, a taxa de crescimento superou os 5\% a.a., durante o periodo de 1984-87. Não há dados para afirmar que essa situação se deva à pequena empresa mas a última década presenciou uma notável explosão da atividade industrial em pequena escala, na cidade de Kumasi. Lá, durante a década de oitenta, o número de artesãos cresceu oito vezes, atingindo a cifra de 40.000. Houve aperfeiçoamento tecnológico, melhoria de qualidade $e$ ampliação da linha de produtos. Em alguns casos, a pequena indústria passou a competir com a média e a grande indústria". ${ }^{11}$

"O equipamento era precário: a maioria destas oficinas apenas dispunha de equipamento manual, sendo raras as que possuiam tornos e outros tipos de maquinaria. As oficinas aceitavam todo o tipo de trabalho, mesmo aquele que, de antemão, sabiam não estarem aptas a concluir. Nesse caso, sub-contratavam os serviços de outras oficinas especializadas, que possuíam os recursos necessários para fazê-lo. Dessa forma, começaram a surgir encomendas de todas as partes de Ghana e até dos países vizinhos. Todo esse grupo de oficinas beneficiou-se dessa eficiência coletiva." 12

A indústria têxtil brasileira também foi estudada, não só a do Nordeste como também a da região Centro-Sul do país. Esta última, próxima dos produtores de equipamentos, como teares, veio realçar, mais uma vez, a importância do fator "proximidade geográfica" de várias espécies de fornecedores de tecnologia.

É essencial, para pequenas firmas, a disponibilidade de serviço de manutenção e comércio especializado de peças e partes de equipamento. Em contraste, aglomerados uni-especializados, isto é, de fabricantes do mesmo produto, não oferecem nenhuma vantagem. A eficácia surge através do desenvolvimento de aglomerados setoriais ${ }^{13}$, capazes de superar descontinuidades tecnológicas.
Não obstante ter-se dito que a EF desenvolveu-se em regiões geograficamente pequenas, ela envolve um número ponderável de trabalhadores, técnicos, artesãos etc. Não se limita a uma cidade, podendo abranger até uma região do país. Esse fenômeno não se reduz à análise microeconômica e também não se ajusta à análise macroeconômica, razão pela qual, tem sido chamada de mezzoeconomia.

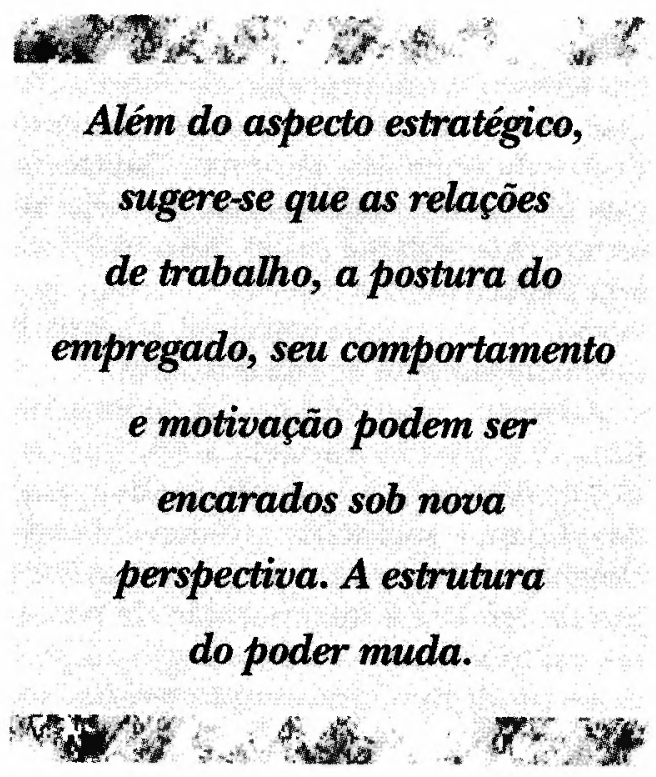

\section{MÃO-DE-OBRA NAS REGIÕES SUBDESENVOLVIDAS}

O farto contingente de mão-de-obra no mercado de trabalho dos países subdesenvolvidos tem implicações deletérias na evolução dos aglomerados que prenunciam o modelo europeu de EF.

As pressões por parte do excedente de mão-de-obra acabam por determinar que o esforço competitivo entre as pequenas manufaturas se faça através da minimização dos salários pagos. A indústria de manufatura de redes no Nordeste é um exemplo de competição através do aviltamento do salário. Essa competição não se realiza pela inovação de processos produtivos/técnicos, mas pelo preço, que é reduzido em conseqüência da baixa remuneração do trabalho. Também não se pensa em termos de qualidade. Em contraste com o modelo europeu, ainda se observa um baixo ní-
10. “Na Grécia, as pequenas $\mathrm{e}$ médias empresas obtiveram melhores resultados que as grandes, durante o período de crise deste país. 0 mesmo ocorreu com as pequenas empresas do Peru. Presume-se serem as empresas de pequeno e médio portes, mais flexíveis que as grandes, muito embora não se possa confundir pequena empresa com EF". Ver SCHMITZ, Hubert. Small firms and flexible specialization in LDCs. São Paulo. mimeo, maio 1989. p. 17. (Tradução do autor)

11. Idem, ibidem.

12. Idem, ibidem.

13. Entende-se por "aglomerado setorial" aquele que envolve indústrias que se complementam. 
14. A partir do momento em que a economia informal assume certo vulto, ela representa um ônus ponderável para os cofres públicos, sem a contrapartida de receitas. Pior: no caso do Peru, estabeleceu-se um mecanismo de escoamento da produção de empresas do setor formal, através da economia informal, o que, evidentemente, é uma distorção inadmissível. 0 mesmo pode ser observado nas feiras de artesanato, no Brasil.

15. BRUSCO, S., RIGHI, Ezio. Local government industrial policy and social consensus: the case of Modena (Italy). Economy and Society, v. 18, n. 4 Nov. 1989.

16. SABEL, C., ZEITLIN, J. Historical alternatives to mass production: politcs, markets and technology in nineteenth century industrialization. Past and Present, 108, 1985. vel tecnológico e ausência de integração com fornecedores de equipamentos, situados em São Paulo, a cerca de 2000 $\mathrm{Km}$ de distância.

\section{O PAPEL DO ESTADO}

Raramente o Estado exerce papel determinante no estabelecimento da EF. Contudo, os governos locais deram sua contribuição, melhorando a infra-estrutura e regulamentando padrões de saúde, de segurança e de salários. De resto, a Especialização Flexível é um fenômeno sócio-técnico e um processo de fabricação que se desenvolveu espontaneamente dentro da economia informal. Crescendo esta última, o Estado geralmente nela interfere, via sistema fiscal. Não obstante seja explicável ${ }^{14}$, a interferência dos governos na economia informal acarreta o desmantelamento de sua estrutura.

Ademais, intervindo na economia informal, o Estado atropela a EF, que indubitavelmente é uma alternativa saudável para a sociedade: promove o crescimento real de empregos, a redistribuição da renda e a incorporação de parcelas marginalizadas da população no processo produtivo, prevenindo tensões sociais mais graves.

Seria precipitado concluir que os governos nunca teriam um papel positivo a desempenhar com respeito à $E F$ ?

Sebastiano Brusco e Ezio Righi ${ }^{15}$ examinam o papel do governo local no caso das políticas industriais adotadas em Modena, uma das províncias da EmiliaRomagna. Três espécies de providências ocorreram: demarcação de terras para parques industriais, financiamentos especiais para pequenas firmas e fornecimento de informação sobre tecnologia $e$ mercados de setores específicos. O projeto não discriminava grandes, médias ou pequenas empresas. Contudo, essas providências foram adotadas com respeito ao setor formal da economia. Com respeito ao setor informal, a própria identificação das unidades produtivas é problemática.

No Brasil, abandonadas à própria sorte, essas estruturas de organização do trabalho que se aproximam do modelo de especialização flexível, dificilmente se articularão conforme o modelo euro- peu. As grandes distâncias entre os fornecedores de tecnologia e as manufaturas, as deficiências de transporte e de comunicações e o baixo nível de qualificação tecnológica das comunidades envolvidas são barreiras que superam os objetivos e a vocação do setor privado. O Estado, que por natureza é responsável pelo bem-estar social, precisa ter o talento de incentivar a EF sem destruir sua espontaneidade.

\section{CONCLUSÕES}

Neste exame do modelo europeu de $\mathrm{EF}$, a intenção foi descobrir condições necessárias de sua existência e também precisar seu conceito. É conveniente lembrar que este estudo não pretendeu exaurir um conjunto completo de condições necessárias que definissem a condição suficiente. De acordo com Sabel e Zeitlin ${ }^{16}$ "as seqüencias do desenvolvimento que conduzem à produção flexivel são tão diversas quanto aquelas que abrem caminho para o uso amplo de máquinas específicas. Colocado de outro modo, as explicações sobre as maneiras pelas quais uma região industrial se desenvolve são tão dificeis de serem reduzidas a uma lista de causas puramente econômicas quanto a identificação de quais regiões (entre tantas possiveis) vão se desenvolver."

Em seguida, foram estudadas algumas estruturas de organização do trabalho que prenunciam a EF em países subdesenvolvidos. Podem-se agora especificar as condições ausentes para o caso do Brasil:

1. um ambiente de mão-de-obra qualificada;

2. fornecedores locais de equipamentos e de tecnologia;

3. conhecimentos sobre as vantagens da EF e sobre as atitudes de colaboração entre pequenas empresas complementares.

O ensino técnico local, que atenderia à primeira condição acima, a médio e longo prazo, poderia ser fornecido pelo SENAI - Serviço Nacional de Aprendizagem Industrial e pelos Colégios Técnicos Federais. A curto e médio prazos, $o$ SEBRAE - Serviço Brasileiro de Apoio às Micro e Pequenas Empresas teria um papel importante a desempenhar. 
Convém mencionar que Schmitz ${ }^{17}$ observa: "com base em estudos de casos no Brasil, a fonte mais importante de qualificação para o trabalho, no âmbito do pequeno produtor, é a experiência prévia em outros empregos." $\mathrm{E}$ também: "O ponto forte do pequeno fabricante é o conhecimento do processo completo".

Não se pretende, portanto, que o sistema formal de educação venha a treinar todos os trabalhadores, da noite para o dia. O processo de "aprender fazendo" é uma característica do sistema informal da economia. O estabelecimento de um consenso social e uma orientação sobre as vantagens da atitude de colaboração são pontos centrais deste tipo de educação fornecida pelo Estado. De resto, nem toda a mão-de-obra que trabalha em unidades produtivas da economia informal é altamente qualificada. Um dos objetivos que se propõem neste estudo é o aproveitamento da mão-de-obra não-qualificada e até mesmo marginalizada. Um emprego, mesmo no setor informal, pode representar um incentivo à qualificação formal, além dos subsídios que o processo de "aprender fazendo" fornece.

Quanto à segunda condição, uma alternativa para evitar a intervenção direta do governo seria a criação de um consórcio temporário ${ }^{18}$ constituído por fundações, federações de indústrias, e outras entidades (como a SUDENE ${ }^{19}$ - Superintendência de Desenvolvimento do Nordeste, no caso do Nordeste), com o objetivo de planejar e implantar pequenas indústrias, para fornecer equipamentos essenciais ou talvez, no início, partes e peças de equipamentos às manufaturas envolvidas. Isso poderia ser feito a partir do que já existe instalado nessas regiões.

A solução da terceira necessidade repousa no ensino de primeiro e segundo graus, por tratar-se da formação de condições básicas favoráveis ao sucesso do modelo. Não se trata aqui de objetivos que poderiam ser atingidos através de treinamento técnico a curto prazo. A rede do SENAI e do SESI - Serviço Social da Indústria, que oferecem cursos de $1^{\circ}$ grau e $2^{\circ}$ graus, também poderia contribuir para isso. $\mathrm{O}$ assunto mereceria um projeto elaborado por equipe interdisciplinar, vista a complexidade do fenômeno, que abrange o nível técnico, o social, o cultural, o econômico e o financeiro.

O Estado e seus mecanismos de planejamento não podem deixar de avaliar esta alternativa promissora nos seus proje-

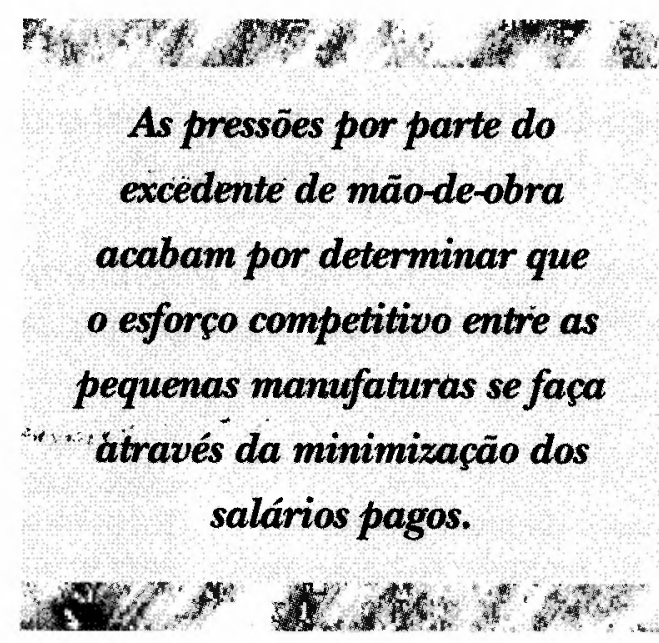

tos de desenvolvimento econômico e social. A EF vem ao encontro da descentralização industrial, (um objetivo atual do governo) da desconcentração do poder econômico, da valorização da qualificação profissional e da democratização dos postos de trabalho. ${ }^{20}$ Promove formas cooperativas de organização econômica, além de integrar mão-de-obra inativa ao processo produtivo, dotando-a de renda, de referenciais de cultura e de incentivo à obtenção de melhor qualificação profissional e, a baixo custo. $\square$

* Muitas idéias deste artigo foram debatidas na conferência Small Firms and Flexible Specialization in LDCs - proferida na FEAUSP, em maio de 1989, pelo Prof. Hubert Schmitz, Sussex University, Inglaterra.

PALAVRAS-CHAVE: Especialização flexível, organização do trabalho, complementaridade produtiva, desenvolvimento econômico, economia informal, nível de empregos, redes de produção, qualificação profissional.

KEY WORDS: Flexible specialization, work organization, economic development, informal economy, production networks, employment level, professional qualification.

17. SCHMITZ, H. Growth constraints on small-scale manufacturing in developing countries: a critical review. World Development, v. 10, n. 6, 1982.

18. Consórcios desse tipo tem ocorrido recentemente, no Brasil e no exterior, com o objetivo de restaurar grandes monumentos históricos. "Mutatis mutandis", por que não aproveitar a idéia neste projeto que beneficia uma causa social?

19. Não se trata de um parodoxo: procura-se evitar apenas que tudo fique sob a égie do governo.

20. ZEITLIN, J. Local industrial strategies: introduction. Economy and Society, v. 18, n. 4, Nov. 1989. 